\title{
Multiple Professional Identities: Examining Differences in Identification Across Work-Related Targets
}

\author{
Michael D. Johnson, Frederick P. Morgeson, Daniel R. Ilgen, Christopher J. Meyer, and James W. Lloyd \\ Michigan State University
}

\begin{abstract}
Although there is a growing literature on organizational identification, relatively little research has investigated other possible targets of identification. In a sample of veterinarians working in a wide range of organizations, the authors compared their identification with the veterinary profession, their organization, and their workgroup. The authors found different patterns of identification across these targets depending on whether the individual (a) worked in a veterinary medicine or nonveterinary medicine organization and (b) was an owner/partner or an associate. Owners of veterinary medicine organizations identified more with the organization than with either the profession or their workgroup. Associates in veterinary medicine organizations identified more with the organization and the workgroup than with the profession. Veterinarians in nonveterinary medicine organizations identified more with the profession and their workgroup than with the organization. Identification with each of the targets provided independent predictive validity of job satisfaction.
\end{abstract}

Keywords: social identity, job satisfaction, teams, professionals, organizational identification

Work-related identities are important to people and often influence their sense of self more than do personal characteristics such as gender, race, or ethnicity (Hogg \& Terry, 2001). Questions of work-related identity and identification arise primarily from social identity and self-categorization theories (Tajfel \& Turner, 1979; Turner, 1985), which suggest that individuals adopt identities on the basis of social referent groups to reduce uncertainty and enhance self-esteem (Hogg \& Terry, 2001). These theories also suggest that individuals hold multiple identities on the basis of various referent groups and that these identities are activated by situational cues. For example, an individual may activate one social identity when at work and a different one when at lunch with friends.

Social identities may be associated with the organization as a whole or subgroups within the organization (Ashforth \& Johnson, 2001). A particularly intriguing but little-studied notion is that individuals may identify with extraorganizational work-related groups such as occupations or professions. According to Hickson and Thomas (1969), occupations fall on a professionalization continuum; the more professional occupations (e.g., medical doctors, attorneys, architects) are distinguished from less professional occupations on 19 dimensions such as specialized education and

Michael D. Johnson, Frederick P. Morgeson, Daniel R. Ilgen, Christopher J. Meyer, Department of Management, Michigan State University; James W. Lloyd, Department of Veterinary Medicine, Michigan State University.

This research was supported by a grant provided by the American Veterinary Medical Association and the National Committee on Veterinary Economic Issues.

Correspondence concerning this article should be addressed to Michael D. Johnson, Department of Management, N475 Business College Complex, Michigan State University, East Lansing, MI 48824. E-mail: johnson@bus.msu.edu skill based on theoretical knowledge (these characteristics are treated in more detail later). Identifying with multiple targets is a challenge for professionals in organizational contexts for at least two reasons. First, professionals may identify more strongly with their profession than with their employing organization, producing potential conflicts between professionals and their organization's expectations for their behavior. Second, professionals may be more committed to their profession than to their employing organization, potentially leading to greater turnover and fewer prosocial organizational behaviors. Thus, we sought to examine the social identification of professionals in various contexts to discover the pattern of identification across multiple targets and the potential impact of multiple identities on organizationally relevant outcomes.

\section{Multiple Work-Related Identities}

In organizational contexts, the vast majority of research has examined an individual's identification with the organization as a whole (e.g., Ashforth \& Saks, 1996; Mael \& Ashforth, 1992; Smidts, Pruyn, \& van Riel, 2001). Organizational identification has been defined as a "psychological attachment that occurs when members adopt the defining characteristics of the organization as defining characteristics of themselves" (Dutton, Dukerich, \& Harquail, 1994, p. 242) and has been found to be an important antecedent to many desired organizational outcomes, including cooperation and effort (Bartel, 2001), intention to remain (Abrams, Ando, \& Hinkle, 1998), and organizational citizenship behaviors (Bergami \& Bagozzi, 2000).

Research has also examined identification with units nested within organizations. Shamir, Zakay, Brainin, and Popper (2000) found that the identification of soldiers with their unit was significantly related to unit discipline and potency. In a sample of government and university employees, van Knippenberg and van 
Schie (2000) found that individuals identified more strongly with their workgroup than they did with the organization as a whole.

In addition to the examination of identification within organizations, similar notions have been used to examine identification with extraorganizational units. Early work studied the relationships between identification and career type (Hall \& Schneider, 1972) as well as formalization and alienation among professionals (Greene, 1978). More recently, in a qualitative study of hospital employees, Pratt and Rafaeli (1997) found that professionals do indeed identify with multiple targets, including their professional medical specialty as well as their work unit in the hospital. Dukerich, Golden, and Shortell (2002) examined the identification of doctors with their health care systems and found that those who identified strongly were more likely to engage in cooperative behaviors within the system. Thus, theory and empirical research suggest that organizational members often identify with multiple work-related targets (e.g., workgroup, organization, larger profession), and these different identification targets have a number of differential organizational implications.

Although various identities become salient because of contextual cues, some identities tend to be more accessible than others because they are more valued or important (Hogg \& Terry, 2001). Forehand, Deshpandé, and Reed (2002) referred to this accessibility as identity strength and defined it as "an enduring association between an individual's sense of self and his or her identity" ( $p$. 1087). People vary in their identity strength with these targets, which influences their behavior toward the various targets.

An additional complicating factor for analyzing the social identification of professionals, however, revolves around the fact that they can work in organizations whose mission is consistent with their profession or in organizations whose mission is not necessarily consistent. In the first type of organization, "the majority of the members are professionals, the professional content of the work is central to the mission of the organization, and the goals of the organization are largely consistent with those of the professionals it employs" (Wallace, 1995, p. 229). Examples of this type of organization include medical clinics, law firms, accounting firms, and research institutes. By contrast, the second type of organization comprises ones in which professionals usually represent a minority of the employees, the professional content of the work is not the central orientation of the organization, and the goals of the organization and the profession are not necessarily consistent. Examples of this type of organization include corporations and government agencies.

We studied professionals in both types of organizations using a national random sample of veterinarians. Veterinarians are both an understudied group in applied psychology and an exemplar of a professional occupation. Hickson and Thomas (1969) developed a list of 19 elements that characterize the professionalization of an occupation. On virtually every element (e.g., specialized education, competence testing, code of conduct and/or ethics, occupational title change, skill based on theoretical knowledge), veterinary medicine falls on or very near the professional pole. Veterinarians in the first of Wallace's (1995) two types of organizations (which we refer to as veterinary medicine organizations) work in veterinary medical practice, in which the mission is the care and treatment of animals; some work with companion animals (e.g., cats and dogs), whereas others work with large animals (e.g., horses and cows), including both equine and food animal practices.
Veterinarians in the second type of organization (which we refer to as nonveterinary medicine organizations) work in government agencies (e.g., the U. S. Department of Agriculture), corporations and/or private industry (e.g., Pfizer, Iams), and academic institutions, in which the missions are not simply the care and treatment of animals. Veterinarians in these organizations develop and monitor compliance with regulations related to the quality of the food chain (e.g., mad cow disease, wasting disease in deer herds) and the protection of animals in research, address epidemiological issues related to animals, conduct basic research, teach, or do a number of other tasks outside the range of activities of a veterinary practice.

\section{Social Identification in Nonveterinary Medicine Organizations}

We predicted that veterinarians would vary in their identification with work-related targets depending on their organization type and ownership status. The nonveterinary medicine organizations in our sample were similar to the organizations in a previous study that found that individuals (who were not professionals) identified more with their workgroup than with the organization as a whole (van Knippenberg \& van Schie, 2000). In general, lower order identities (i.e., workgroups) are more subjectively important to people than are higher order identities (i.e., organizations); that is, people tend to identify more with proximal groups than with distal ones (Ashforth \& Johnson, 2001). Van Knippenberg and van Schie (2000) offered two reasons why this is likely to be the case. First, people are more likely to identify with groups that allow them to retain some sense of distinctiveness (Brewer, 1991). Because workgroups are smaller than the organizations in which they are embedded, identifying with workgroups allows individuals to feel connected to others without being overwhelmed by the group identity. Second, people tend to have more in common with those in their workgroup than with other organizational members. Their common work history and related tasks increase their identification with the workgroup because people are likely to identify with groups that they perceive to be similar to themselves (Turner, 1985). Finally, Ashforth and Johnson (2001) offered an additional reason why people should generally identify more with their workgroup than with their organization: The shift from commandand-control organizational structures to more organic ones has increased lateral communication and teamwork, causing people to vest more of their identity at the level of the workgroup rather than at the level of the organization. On the basis of these arguments, we expected the following:

Hypothesis 1: Veterinarians in nonveterinary medicine organizations identify more strongly with their workgroup than with their organization as a whole.

Gouldner $(1957,1958)$ outlined a potential conflict inherent in the professional employment situation. He expressed this in terms of the "cosmopolitan-local" tension created by two latent identities negatively related to each other. One identity was to the profession or career relatively independent of the immediate community in which the person was located. Those who assumed this identity were called cosmopolitans and lacked loyalty to the employing organization, were highly committed to specialized role 
skills, and were likely to take as their reference group individuals outside the employing organization. By contrast, locals were loyal to the employing organization, were not particularly highly committed to specialized role skills, and were likely to use an inner reference-group orientation.

Subsequent studies found that cosmopolitan and local orientations were separate dimensions (Glaser, 1963; Stahl, Manley, \& McNichols, 1978). Instead of resembling a zero-sum game, orientations of professionals may be to their profession, their organization, both, or neither. In one study that examined the commitment orientation of lawyers in both law firms and corporations, Wallace (1995) found, somewhat surprisingly, that lawyers only in corporations were less committed to their profession than to their employing organization.

Just as commitments can vary, so too can identification. Although one might expect that identification would follow a similar pattern to commitment, social identity theory suggests otherwise. One of the basic tenets of the theory is the social attraction hypothesis - that people identify more strongly with groups that enhance their self-esteem (Hogg \& Terry, 2001). Indeed, prestige has been shown to be a significant predictor of organizational identification in several studies (e.g., Bergami \& Bagozzi, 2000; Mael \& Ashforth, 1992). In nonveterinary medicine organizations, this should lead veterinarians to identify with the vocational groups that are the most prestigious. Because professional occupations tend to be more prestigious than nonprofessional ones, we expected that veterinarians in nonveterinary medicine organizations would identify more strongly with the profession, as this identity would set them apart from the nonveterinarians in their organizations.

Hypothesis 2: Veterinarians in nonveterinary medicine organizations identify more strongly with their profession than with their organization.

\section{Social Identification in Veterinary Medicine Organizations}

Two distinct types of professionals work in veterinary medicine organizations: owners/partners and associates. Owners/partners tend to be older and have more tenure with their particular organization. Tenure has been shown to be associated with higher strength of organizational identification (Bartel, 2001; Mael \& Ashforth, 1992). Beyond this, ownership carries more significant implications for personal identity; in some sense, one's property represents an extension of the self (Belk, 1991). According to Pierce, Kostova, and Dirks (2001), possessions become part of the owner's identity through the owner's sense of control over, intimate knowledge of, and investment into them. Supporting this notion, empirical research has shown that employee stock ownership programs have had a positive effect on many individual psychological variables, including organizational identification (French \& Rosenstein, 1984; Klein, 1987; Long, 1978). Because veterinary medicine organizations tend to be much smaller than corporations, we expected that this effect would be even more pronounced because the owners possess a greater share of the organization.

In contrast, although we expected owners to feel some identification with the employees who make up their workgroup, we expected that the identification would be less than to the practice (organization) itself. For owners, their workgroup reflects the people with whom they work on a day-to-day basis. In veterinary practices, owners tend to work side by side with technicians, other veterinarians who are associates of the practice, receptionists, and others in a confined physical space that leads to very frequent daily interactions and fosters the creation of a team or workgroup. Nevertheless, the coworkers of a veterinary medical practice (other owner/partners, associates, technicians, and office staff) represent less of a possession to owners than does the practice as a business entity. Additionally, owners tend to have longer amounts of time associated with the practice than with the current workgroup members because of staff turnover. Thus, we expected the following:

Hypothesis 3: Veterinarians who are owners/partners in veterinary medicine organizations identify more strongly with their organization as a whole than with their workgroup.

Using the same logic for owners/partners in veterinary medicine organizations pertaining to their identification with the workgroup versus their identification with the organization, we expected that the "extension of self" dynamic of property ownership (Belk, 1991) would cause owners/partners to identify more strongly with their organization than with their profession. Although owners by definition have at least as much tenure with the profession as with the organization, they are likely to have far less control over, knowledge of, and investment in the profession in general relative to their practice. Therefore, we expected the following:

Hypothesis 4: Veterinarians who are owners/partners in veterinary medicine organizations identify more strongly with their organization than with their profession.

In contrast to owners/partners in veterinary medicine organizations, associates are generally younger and relatively new to their organization and the field. Ashforth and Mael (1989) asserted that for organizational newcomers, individual "self-definitions are apt to be largely subunit-specific" (p. 29). Organizational newcomers develop identities on the basis of their subunit, rather than the organization as a whole, because of proximity and greater interaction and similarity with coworkers in their subunit than with other organizational members. Additionally, the arguments advanced for why veterinarians in nonveterinary medicine organizations should identify more with their workgroup than their organization should also apply here: Associates should identify more with their workgroup because of frequent interaction, common work history, and related tasks.

Hypothesis 5: Professionals who are associates in veterinary medicine organizations identify more strongly with their workgroup than with their organization as a whole.

Because associates in veterinary medicine organizations are generally new to both the profession and the organization (and indeed the associates in our study were on average 10 years younger than the owners and those in nonveterinary medicine organizations), one might expect that there would not be differences in their identification with these targets. We offer three reasons, however, as to why associates may identify more with the profession than with their employing organization. First, profes- 
sional schools serve to socialize students to the profession, facilitating the adoption of their new occupational identity (H. S. Becker \& Carper, 1956). Students in professional schools define themselves increasingly in terms of their profession as they progress through school (Kuhn, 1960). Second, sunk costs have been shown to increase commitment to a course of action (Garland, 1990). The sunk costs of finances and time required to complete professional school are expected to increase commitment to the profession. Third, studies of intrinsic motivation have shown that individuals attribute their motivation to internal causes when rewards are low (Deci, Benware, \& Landy, 1974). Professionals who are associates earn relatively low salaries compared with others in their profession but often must work longer hours on less attractive tasks. We expected that this would lead associates to attribute their motivation for their behavior to internal commitment to the profession, which again should increase their identification with the profession. On the basis of these arguments, we expected the following:

Hypothesis 6: Professionals who are associates in veterinary medicine organizations identify more strongly with their profession than with their organization.

\section{Social Identification and Job Satisfaction}

A positive relationship between identification with the organization and job satisfaction has been established by numerous studies (Ashforth \& Saks, 1996; Mael \& Ashforth, 1992; Mael \& Tetrick, 1992; Saks \& Ashforth, 1997). This finding is not surprising, in part because both constructs involve beliefs and feelings about one's relationship to the organization. What is not clear from the literature, however, is whether job satisfaction is independently influenced by identification with different organizational targets.

Past research has indicated that job satisfaction in organizational contexts is a function of the individual's relationship with multiple targets. For example, T. E. Becker (1992) found that commitment to the organization, top management, and workgroup all contributed independently to both intrinsic and extrinsic satisfaction. Similarly, trust in both one's direct supervisor and in organizational leaders appears to be important in predicting job satisfaction (Dirks \& Ferrin, 2002). From a social identity perspective, identification with social groups serves to meet individual needs, including the needs for safety, affiliation, self-enhancement, and a sense of purpose (Pratt, 1998). Identifying with multiple workrelated targets is likely to meet more of these needs, and this should in turn have a positive effect on job satisfaction. Thus, we predicted that identification with the organization, workgroup, and profession should all independently contribute to professionals' job satisfaction.

Hypothesis 7: Organizational, professional and workgroup identification each uniquely predict job satisfaction.

\section{Method}

\section{Sample and Survey Methodology}

A national stratified random sample of 1,750 veterinarians was obtained from the American Veterinary Medical Association (AVMA; the main professional organization for the field of veterinary medicine). The sample was stratified along career foci, including 250 veterinarians in each of seven career foci (companion animal, equine, food animal, mixed animal, academic, government, and industry). A letter requesting participation in the study, along with a return postcard to indicate willingness to participate, was sent to all of the veterinarians in the sample. Fourteen letters were returned undelivered, resulting in a total sample pool of 1,736. Following the initial and follow-up mailings to those from whom responses were not returned, $764(44 \%)$ veterinarians returned the postcard indicating their willingness to receive a survey. Of these, 590 actually completed and returned the survey, yielding a response rate of $77 \%$ of those who returned the initial postcard and $34 \%$ of the total sample. All received $\$ 10.00$ for completing the survey.

On the basis of data provided by the AVMA, we were able to compare respondents with nonrespondents on gender and year of graduation from veterinary school. In terms of graduation year, there was no significant difference between respondents $(M=1983.57, S D=10.75)$ and nonrespondents $(M=1982.64, S D=10.59, n s)$. In terms of gender, however, a higher percentage of the women responded to the survey $(66 \%)$ than the men, $45 \%, \chi^{2}(1, N=1,736)=13.94, p<.01$. The final sample was $61 \%$ male and $39 \%$ female, whereas the initial pool was $67 \%$ male and $33 \%$ female. Although this differential response indicates the sample is not completely representative of the current veterinarian population, it is consistent with work that shows the percentage of female veterinarians to be increasing (Ilgen et al., 2003). This suggests that the data are representative of larger trends in the profession.

\section{Measures}

All measures for analyses were collected on a single questionnaire mailed to the veterinarians. Although such data have the potential for response-response biases, our interests were not in the simple covariation between perceptual measures. Variables with low probabilities of perceptual bias, specifically responses to factual questions about employment relationships such as whether the veterinarian was the owner of the practice, whether he or she was employed by a government agency, was a professor at a university, and so forth were used to partition the sample. The primary analyses were then based on comparisons of the patterns of relationships within subsamples. Observed patterns of results from these comparisons were unlikely to be systematically affected by the responseresponse nature of the data; whatever response-response bias was present in one sample should have been present in another and not produce differences between groups. Because we used a within-subjects research design for Hypotheses 1-6, the participants served as their own control (Pedhazur, 1982) and were perfectly matched on every variable (e.g., age, sex, ethnicity, tenure) across identification targets. Although individual difference variables (e.g., organizational tenure) may account for betweensubjects variance, they cannot by definition account for any within-subjects variance.

Identification. Identification was measured with a six-item scale (Mael \& Ashforth, 1992); identification with each target was measured by inserting the words veterinary medicine, practicelorganization, and workgroup in the place of organization in each identification item. For example, an item began with the stem, "I am very interested in what others think about" and ended with "veterinary medicine," "my practice/organization," or "my workgroup" on the professional, organizational, and workgroup scales, respectively. Because the formal definition of workgroups may vary across organizations, workgroup was operationalized on the survey as "the people with whom you work; coworkers." Responses were given on a 5-point scale, ranging from 1 (strongly disagree) to 5 (strongly agree); coefficient alpha was .84 for the profession, .89 for the organization, and .90 for the workgroup.

Job satisfaction. Job satisfaction was measured with the 20-item Minnesota Satisfaction Questionnaire (Weiss, Dawis, \& England, 1967). Responses were given on a 5-point scale, and alpha was .90. 
Employment type. The organization type (veterinary medicine or nonveterinary medicine) and ownership status were measured with single self-report items. We assessed organization type by using terms taken from the AVMA, which assesses organization type by asking about respondents' career focus. Veterinarians who indicated that they worked in academic institutions, government agencies, or in industry were classified as working in nonveterinary medicine organizations. Veterinarians who worked in a veterinary medical practice (companion animal, equine, food animal, or mixed animal) were classified as working in veterinary medicine organizations. Ownership status was determined by their response to the question "If in a practice, are you an owner/partner or an associate?"

Control variables. Age, gender, and organizational tenure were measured through single self-report items.

\section{Results}

\section{Targets of Identification}

Table 1 shows the means, standard deviations, and intercorrelations of the scales for each of the subgroups of veterinarians. Hypotheses 1-6 were analyzed with the repeated measures func- tion of the General Linear Model in SPSS 11.0 and paired sample $t$ tests. The repeated measures test allowed us to decompose how much of the variance in identification was due to within-subjects effects (target of identification) and how much was due to between-subjects effects (type of employment) and provide an omnibus test of differences across targets and employment status. The paired sample $t$ tests then allowed us to test simple differences in identification across targets within each type of employment, providing direct tests of Hypotheses 1-6. We examined effect sizes $(d)$ in addition to testing for statistical significance. Cohen (1988) suggested that $d$ values around .20 typically represent small effects, $d$ values around .50 represent medium effects, and $d$ values above .80 represent large effects.

In the omnibus repeated-measures test, the within-subjects factor was the target of identification, and employment status was the between-subjects factor. Age, gender, and organizational tenure were included as covariates. As can be seen from Table 2, the univariate between-subjects test showed that two main effects were significant: employment type, $F(1,517)=15.85, p<.01$,

Table 1

Zero-Order Correlations, Means, Standard Deviations, and Reliabilities of the Scales

\begin{tabular}{|c|c|c|c|c|c|c|c|c|c|}
\hline Entire sample $(N=523)$ & $M$ & $S D$ & 1 & 2 & 3 & 4 & 5 & 6 & 7 \\
\hline 1. Age (years) & 45.36 & 9.72 & - & & & & & & \\
\hline 2. Gender ${ }^{\mathrm{a}}$ & 0.39 & 0.49 & $-.35 * *$ & - & & & & & \\
\hline 3. Organizational tenure (years) & 13.62 & 9.80 & $.62 * *$ & $-.29 * *$ & - & & & & \\
\hline 4. Professional identification & 4.01 & 0.63 & .06 & $-.11 *$ & .04 & $(.81)$ & & & \\
\hline 5. Organizational identification & 4.10 & 0.73 & .07 & $-.17 * *$ & $.15^{* *}$ & $.47 * *$ & $(.89)$ & & \\
\hline 6. Workgroup identification & 4.17 & 0.67 & $.09 *$ & $-.12 * *$ & $.09 *$ & $.39 * *$ & $.56^{* *}$ & $(.88)$ & \\
\hline 7. Job satisfaction & 3.86 & 0.52 & $.21 * *$ & $-.18 * *$ & $.20 * *$ & $.30 * *$ & $.42 * *$ & $.36^{* *}$ & $(.90)$ \\
\hline Vets in nonveterinary medicine organizations $(n=267)$ & $M$ & $S D$ & 1 & 2 & 3 & 4 & 5 & 6 & 7 \\
\hline 1. Age (years) & 47.90 & 9.10 & - & & & & & & \\
\hline 2. Gender ${ }^{\mathrm{a}}$ & 0.39 & 0.49 & $-.34 * *$ & - & & & & & \\
\hline 3. Organizational tenure (years) & 12.74 & 9.35 & $.47 * *$ & $-.17 * *$ & - & & & & \\
\hline 4. Professional identification & 3.97 & 0.61 & $.15^{*}$ & -.10 & .01 & $(.81)$ & & & \\
\hline 5. Organizational identification & 3.86 & 0.72 & $.29 * *$ & $-.21 * *$ & $.18 * *$ & $.45 * *$ & $(.87)$ & & \\
\hline 6. Workgroup identification & 4.17 & 0.61 & $.18 * *$ & -.12 & $.15^{*}$ & $.33 * *$ & $.56 * *$ & $(.86)$ & \\
\hline 7. Job satisfaction & 3.82 & 0.51 & $.19 * *$ & -.08 & .08 & $.26 * *$ & $.41 * *$ & $.34 * *$ & $(.90)$ \\
\hline Owners $(n=153)$ & $M$ & $S D$ & 1 & 2 & 3 & 4 & 5 & 6 & 7 \\
\hline 1. Age (years) & 46.22 & 8.95 & - & & & & & & \\
\hline 2. Gender ${ }^{\mathrm{a}}$ & 0.24 & 0.43 & $-.24 * *$ & - & & & & & \\
\hline 3. Organizational tenure (years) & 18.02 & 10.19 & $.84 * *$ & $-.27 * *$ & - & & & & \\
\hline 4. Professional identification & 4.16 & 0.66 & -.07 & -.09 & -.06 & $(.82)$ & & & \\
\hline 5. Organizational identification & 4.53 & 0.56 & $-.17 *$ & .01 & -.15 & $.56^{* *}$ & $(.86)$ & & \\
\hline 6. Workgroup identification & 4.28 & 0.70 & $-.16^{*}$ & -.04 & -.12 & $.47^{* *}$ & $.65^{* *}$ & $(.90)$ & \\
\hline 7. Job satisfaction & 4.07 & 0.44 & .05 & $-.18^{*}$ & .14 & $.42 * *$ & $.34 * *$ & $.39 * *$ & $(.88)$ \\
\hline Associates $(n=103)$ & $M$ & $S D$ & 1 & 2 & 3 & 4 & 5 & 6 & 7 \\
\hline 1. Age (years) & 37.50 & 8.24 & - & & & & & & \\
\hline 2. Gender ${ }^{\mathrm{a}}$ & 0.63 & 0.49 & $-.29 * *$ & - & & & & & \\
\hline 3. Organizational tenure (years) & 9.36 & 7.71 & $.80 * *$ & $-.36^{* *}$ & - & & & & \\
\hline 4. Professional identification & 3.91 & 0.62 & -.04 & -.02 & .03 & $(.77)$ & & & \\
\hline 5. Organizational identification & 4.08 & 0.68 & -.02 & -.08 & .07 & $.39 * *$ & $(.89)$ & & \\
\hline 6. Workgroup identification & 4.02 & 0.75 & .10 & -.09 & .10 & $.35^{* *}$ & $.56^{* *}$ & $(.90)$ & \\
\hline 7. Job satisfaction & 3.65 & 0.55 & $.25 * *$ & -.12 & $.21 *$ & .13 & $.37 * *$ & $.32 * *$ & $(.89)$ \\
\hline
\end{tabular}

Note. Coefficient alpha is on the diagonal.

${ }^{\mathrm{a}}$ Men $=0$; women $=1$.

$* p<.05$. $* * p<.01$. 
partial $\eta^{2}=.06$, indicating that the veterinarians showed differences in identification as a whole depending upon whether they were owners, associates, or worked in nonveterinary medicine organizations; and the control variable gender, $F(1,517)=5.54$, $p=.02$, partial $\eta^{2}=.01$, indicating that men identified more strongly than did women across all three targets. The withinsubjects tests showed that there was no main effect for target for identification for the sample as a whole, $F(1.956,1011.06)=0.80$, $n s^{1}$, meaning that the veterinarians as a whole did not identify more strongly with one of the targets than with the others. The target by employment type interaction, however, was statistically significant, $F(3.911,1011.06)=18.72, p<.01$, partial $\eta^{2}=.07$, indicating that the patterns of identification across the three targets differed by employment type.

With this omnibus test in hand, we then proceeded with direct tests of the hypotheses using paired sample $t$ tests. Hypotheses 1 and 2 predicted that veterinarians in nonveterinary medicine organizations would identify more with their workgroup and profession than with their employing organization. Table 3 presents the mean differences and the $d$ statistic between the targets of identification for veterinarians in nonveterinary medicine organizations, those who were owners/partners in veterinary medicine organizations, and those who were associates in veterinary medicine organizations; Figure 1 displays these results graphically. For the veterinarians in nonveterinary medicine organizations, two of the $d$ statistics were greater than .20 , and one of them approached the moderate effect size of .50. Veterinarians in nonveterinary medicine organizations identified more with their workgroup than with their organization, $t(266)=-7.99, p<.01$, and they identified more with the profession than they did with their particular organization, $t(266)=-2.57, p=.01$. Although we did not predict it, they also identified more with their workgroup than they did with the profession, $t(266)=-4.51, p<.01$. Thus, both Hypotheses 1 and 2 were supported.

Hypotheses 3 and 4 predicted that veterinarians who were owners/partners in veterinary medicine organizations would identify more with their organization than with their workgroup or their profession. Supporting these hypotheses, veterinarians who were owners/partners identified more with their organization than with

Table 2

Repeated Measures Analysis of Variance for Identification

\begin{tabular}{lclc}
\hline \multicolumn{1}{c}{ Variable } & $F$ & \multicolumn{1}{c}{$d f \mathrm{~s}$} & Partial $\eta^{2}$ \\
\hline Age (A) & 1.51 & 1,517 & .00 \\
Gender (G) & $5.54^{\mathrm{a}}$ & 1,517 & .01 \\
Organizational tenure (T) $_{\text {Employment type (E) }}$ & 0.11 & 1,517 & .00 \\
Target of identity (I) & $15.85^{* *}$ & 2,517 & .06 \\
$\mathrm{I} \times \mathrm{A}$ & 0.80 & $1.956,1011.06^{\mathrm{b}}$ & .00 \\
$\mathrm{I} \times \mathrm{G}$ & 0.90 & $1.956,1011.06^{\mathrm{b}}$ & .00 \\
$\mathrm{I} \times \mathrm{T}$ & 0.38 & $1.956,1011.06^{\mathrm{b}}$ & .00 \\
$\mathrm{I} \times \mathrm{E}$ & 0.90 & $1.956,1011.06^{\mathrm{b}}$ & .00 \\
\hline
\end{tabular}

Note. $\quad N=523$.

${ }^{\mathrm{a}}$ Men $=0$; women $=1$.

${ }^{\mathrm{b}}$ Huynh-Feldt correction was applied to the within-subjects degrees of freedom. This correction is applied when the data do not meet the sphericity assumption of repeated measures designs and results in a more conservative test by reducing the degrees of freedom.

$* p<.05$. ** $p<.01$.
Table 3

Paired Sample t Tests of Mean Differences Between Identity Targets by Subgroup

\begin{tabular}{lcccc}
\hline \multicolumn{1}{c}{ Comparison } & $M$ difference & $S D$ & $t^{\mathrm{a}}$ & $d$ \\
\hline \multicolumn{4}{c}{ Nonveterinary medicine organizations $(n=267)$} \\
& & & & \\
Organization-profession & $-0.11 * *$ & 0.70 & -2.57 & -0.16 \\
Organization-workgroup & $-0.31 * *$ & 0.71 & -7.99 & -0.58 \\
Profession-workgroup & $-0.20^{* *}$ & 0.63 & -4.51 & -0.28 \\
\hline
\end{tabular}

Veterinary medicine organization owners/partners $(n=153)$

$\begin{array}{lrrrr}\text { Organization-profession } & 0.37 * * & 0.58 & 7.85 & 0.63 \\ \text { Organization-workgroup } & 0.24 * * & 0.55 & 5.49 & 0.44 \\ \text { Profession-workgroup } & -0.12 * & 0.70 & -2.16 & -0.17\end{array}$

Veterinary medicine organization associates $(n=103)$

$\begin{array}{lllll}\text { Organization-profession } & 0.17 * & 0.72 & 2.44 & 0.24\end{array}$ $\begin{array}{llllr}\text { Organization-workgroup } & 0.06 & 0.68 & 0.96 & 0.09\end{array}$

$\begin{array}{lllll}\text { Profession-workgroup } & -0.11 & 0.79 & -1.40 & -0.14\end{array}$

${ }^{a}$ For nonveterinary organizations, $d f=266$; for veterinary medicine organization owners/partners, $d f=152$; for veterinary medicine organization associates, $d f=102$.

$* p<.05$. ** $p<.01$

their workgroup, $t(152)=5.49, p<.01$, or the profession, $t(153)=7.85, p<.01$. The $d$ statistic for the mean difference between organization and profession was well above the moderate effect size.

Hypothesis 5 predicted that associates in veterinary medicine organizations would identify more with their workgroup than with their organization. For veterinarians who were associates in veterinary medicine organizations, however, there was no significant difference between their organizational identification and their workgroup identification, $t(102)=0.96, n s$; thus, Hypothesis 5 was not supported. Hypothesis 6 predicted that associates would identify more with the profession than with the organization. The mean difference was statistically significant, $t(102)=2.44, p=$ .02 , but was in the opposite direction of what we predicted. Thus, Hypothesis 6 was not supported.

\section{Job Satisfaction}

Hypothesis 7 predicted that identification with each target would independently predict job satisfaction. The effects of the various targets of identification on job satisfaction were tested with hierarchical regression. The control variables were entered in the first step, and identification with the three targets was entered in the second step. As can be seen from the results in Table 4, two of the control variables showed a significant effect on satisfaction: age $(\beta=.12, p<.05)$, indicating that older veterinarians were more satisfied than younger ones; and gender $(\beta=-.11, p<.05)$, indicating that men were more satisfied than women (although the

\footnotetext{
${ }^{1}$ The Huynh-Feldt correction was applied to the degrees of freedom of the within-subjects tests because the data did not meet the sphericity assumption. This results in a more conservative test by reducing the degrees of freedom.
} 


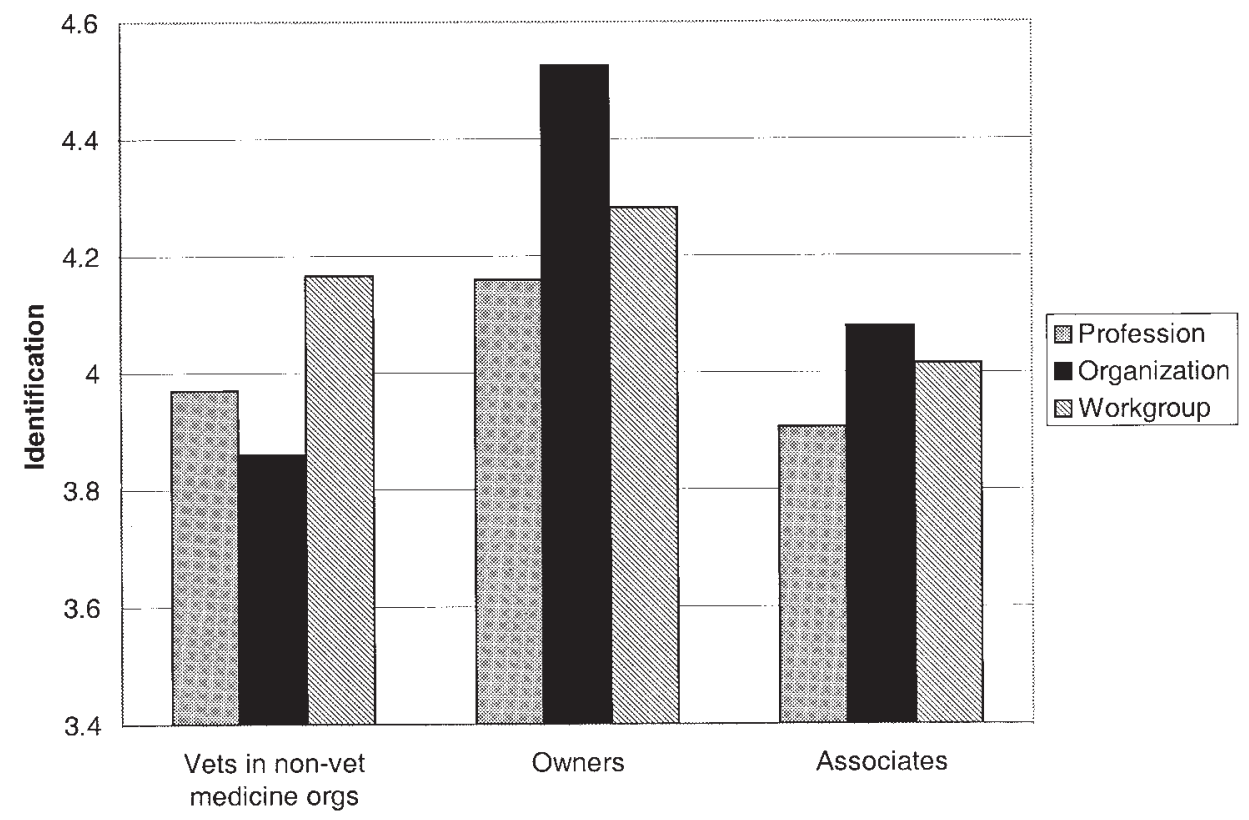

Figure 1. Plot of mean differences of identification for veterinarians in nonveterinary medicine organizations, owners in veterinary medicine organizations, and associates in veterinary medicine organizations.

effect of gender became nonsignificant when the identity variables were entered in Step 2). Together, the controls accounted for $6.3 \%$ of the variance in job satisfaction. All three of the regression weights for identification targets were significant, indicating they each have unique predictive power; together, they accounted for $18 \%$ of the variance in job satisfaction. Thus, Hypothesis 7 was supported.

\section{Discussion}

Our data show that veterinarians identify differently with professional, organizational, and workgroup targets, and the strength of their identification with each target is dependent on their employment situation. Veterinarians in nonveterinary medicine organizations identify less with the organization than with the profession or their workgroup, owners identify more with the

Table 4

Summary of Hierarchical Regression Analysis of Job Satisfaction on Identity Target Scales and Controls

\begin{tabular}{lcc}
\hline \multicolumn{1}{c}{ Variable } & Step 1 & Step 2 \\
\hline Age (years) & $.11^{*}$ & $.12^{*}$ \\
Gender & $-.11^{*}$ & -.05 \\
Organizational tenure & .10 & .05 \\
Professional identification & & $.10^{*}$ \\
Organizational identification & & $.26^{* *}$ \\
Workgroup identification & $11.58^{* *}$ & $.16^{* *}$ \\
$F$ & 3,519 & $27.60^{* *}$ \\
$d f$ & .06 & 6,516 \\
Total $R^{2}$ & & .24 \\
\hline
\end{tabular}

Note. $\quad N=523$.

$* p<.05$. ** $p<.01$. organization than with either the profession or their workgroup and associates identify more with the organization and the workgroup than with the profession.

The workgroup/organization difference among veterinarians in nonveterinary medicine organizations confirms the work by van Knippenberg and van Schie (2000) and provides evidence that in organizational settings, it may be the norm for individuals to identify most highly with more proximal organizational units. The profession/organization difference supports social identity theory's social attraction hypothesis that individuals identify with groups that are prestigious or distinctive and enhance self-esteem. This is an important finding because an increasing number of professionals are working in nonveterinary medicine organizations, partly because of the specialization demands of industry, which require the hiring of more professionals (Wallace, 1995). There is no reason to believe that these professionals will not identify with some work-related target, but our data show that they identify with the organization less than with either their workgroup or the profession.

In contrast, veterinarians who are owners/partners in veterinary medicine organizations identify more strongly with their organization than with their workgroup or profession. This provides general support for the idea that possessions represent an extension of the self, and ownership of an organization holds important implications for identity. Veterinarians who are associates in veterinary medicine organizations exhibit a pattern of identification that is similar to owners, with one notable exception: Their strength of organization and workgroup identification is roughly equivalent. Perhaps this is because most veterinary practices tend to be relatively small, and there is essentially no difference to associates between their organization and their workgroup. Associates do, however, identify differently with their profession and their organization, although the direction was opposite of what we 
predicted: They identify more with their organization than with their profession. This finding may be because of the "imposter phenomenon" (Clance \& Imes, 1978), which occurs when individuals experience a sense of internal phoniness and believe they have fooled others into believing they are something they are not. In professional occupations, associates are expected to be experts in their field but lack extensive experience. This psychological process may lead associates to actually decrease their identification with the profession compared with their identification with the organization; they may not feel comfortable with a professional self-definition but may feel comfortable defining themselves as employees of a particular organization.

In sum, it appears that, for professionals, identification with the organization is less likely when the organization is not integrally linked to their profession. We suspect that this general pattern holds not just for veterinarians but for those in other professional occupations as well (e.g., academics may generally identify less with their university than with their field of study, medical doctors may identify less with the company they work for than with the medical profession).

Our data also indicate that all three targets of identification are important in the prediction of job satisfaction. Whereas previous research has focused primarily on identification with the organization, it appears that identification with one's workgroup and with one's profession is also related to satisfaction, over and above the effects of organizational identification. This supports the notion from social identity theory that multiple identities are important to people; in our case, multiple work-related identities are important in determining how satisfied veterinarians are with their jobs.

\section{Directions for Future Research}

The findings of this study have several important implications. First, because individuals tend to cooperate more with those whom they consider to be part of their in-group, the finding that those in nonveterinary medicine organizations identify more strongly with their profession than with their organization implies that they may be likely to cooperate more with other professionals outside of their employing organization than with nonprofessionals within their employing organization. We suggest that this would be a fruitful avenue for future research on veterinarians in nonveterinary medicine organizations or other professionals employed by corporations or government agencies.

Second, because people tend to compete with others outside of their in-group, professionals who are owners/partners are more likely to see other practices as competition, rather than as other practicing professionals with whom they would cooperate. Indeed, personal discussions with several independent practice owners prior to this study support this assertion. This seems to be in contrast to the more traditional definitions of professional occupations, which emphasize the importance of altruistic behavior for the good of others, as well as expectations of professional collaboration (Cruess, Johnston, \& Cruess, 2004; Hickson \& Thomas, 1969; Locke, 2001). Future research could examine the cooperative behavior of other professionals (e.g., doctors, attorneys, architects) to determine whether professional expectations of altruism and collaboration would win out over the assertions of social identity theory.
Third, although our research questions involved only withinsubjects comparisons, between-subjects comparisons may also be interesting. For example, owners clearly identify more strongly with all of the targets than associates do, which may be because of their relative tenure with the organization, the "extension of self" hypothesis put forward in this article, or the different roles being enacted. It would be interesting to untangle the reasons behind this and other between-subjects comparisons. Fourth, because our research design was cross-sectional in nature, we could not investigate how identification with each of these targets changes over time. It would be interesting to examine such changes. For example, newcomers to the profession may develop differing identification trajectories depending on the type of organization they work in. Finally, we suggest that a fruitful line of research might be to assess the unique effects of identification with various workrelated targets on multiple outcomes, including task performance, contextual performance, absenteeism, and turnover, and to assess the moderating effects of employment type or context on these relationships.

\section{Limitations}

There are at least two limitations of this study. First, in keeping with Hickson and Thomas's (1969) definition of professions, occupations fall on a continuum between poles of professional and nonprofessional. Therefore, these data provide evidence at a particular point on this continuum. Because veterinary medicine meets all of the characteristics in Hickson and Thomas's definition of a profession, it occupies a point near the professional end of the continuum. Further research is needed to focus on occupations that are nearer the middle of the continuum or that are in the process of professionalizing (e.g., teaching, nursing).

Second, there may be other unique aspects of the profession of veterinary medicine that distinguish it from other professions. For example, veterinarians earn significantly less than do medical doctors, yet the qualifications for becoming a veterinarian (in terms of test scores required for entrance into graduate school, and years and rigor of education) are at least as stringent as those for becoming a doctor of human medicine. It may be that veterinarians enter their profession for different reasons or may possess more intrinsic motivation to work in their profession than do those in other professions. Thus, further research on other professions is needed to ensure generalizability of the results.

\section{References}

Abrams, D., Ando, K., \& Hinkle, S. (1998). Psychological attachment to the group: Cross-cultural differences in organizational identification and subjective norms as predictors of workers' turnover intentions. Personality and Social Psychology Bulletin, 24, 1027-1039.

Ashforth, B. E., \& Johnson, S. A. (2001). Which hat to wear? The relative salience of multiple identities in organizational contexts. In M. A. Hogg \& D. J. Terry (Eds.), Social identity processes in organizational contexts (pp. 31-48). Philadelphia: Psychology Press.

Ashforth, B. E., \& Mael, F. A. (1989). Social identity theory and the organization. Academy of Management Review, 14, 20-39.

Ashforth, B. E., \& Saks, A. M. (1996). Socialization tactics: Longitudinal effects on newcomer adjustment. Academy of Management Journal, 39, $149-178$.

Bartel, C. A. (2001). Social comparisons in boundary-spanning work: 
Effects of community outreach on members' organizational identity and identification. Administrative Science Quarterly, 46, 379-413.

Becker, H. S., \& Carper, J. W. (1956). The development of identification with an occupation. American Journal of Sociology, 61, 289-298.

Becker, T. E. (1992). Foci and bases of commitment: Are they distinctions worth making? Academy of Management Journal, 35, 232-244.

Belk, R. W. (1991). The ineluctable mysteries of possessions. Journal of Social Behavior and Personality, 6, 17-55.

Bergami, M., \& Bagozzi, R. P. (2000). Self-categorization, affective commitment and group self-esteem as distinct aspects of social identity in the organization. British Journal of Social Psychology, 39, 555-577.

Brewer, M. B. (1991). The social self: On being the same and different at the same time. Personality and Social Psychology Bulletin, 17, 475482.

Clance, P. R., \& Imes, S. A. (1978). The imposter phenomenon in high achieving women: Dynamics and therapeutic intervention. Psychotherapy: Theory, Research \& Practice, 15, 241-247.

Cohen, J. (1988). Statistical power analysis for the behavioral sciences (2nd ed.). New York: Academic Press.

Cruess, S. R., Johnston, S., \& Cruess, R. L. (2004). "Profession": A working definition for medical educators. Teaching and Learning in Medicine, 16, 74-76.

Deci, E. L., Benware, C., \& Landy, D. (1974). The attribution of motivation as a function of output and rewards. Journal of Personality, 42, 652-667.

Dirks, K. T., \& Ferrin, D. L. (2002). Trust in leadership: Meta-analytic findings and implications for research and practice. Journal of Applied Psychology, 87, 611-628.

Dukerich, J. M., Golden, B. R., \& Shortell, S. M. (2002). Beauty is in the eye of the beholder: The impact of organizational identification identity and image on the cooperative behaviors of physicians. Administrative Science Quarterly, 47, 507-533.

Dutton, J. E., Dukerich, J. M., \& Harquail, C. V. (1994). Organizational images and member identification. Administrative Science Quarterly, 39, 239-263.

Forehand, M. R., Deshpandé, R., \& Reed, A. (2002). Identity salience and the influence of differential activation of the social self-schema on advertising response. Journal of Applied Psychology, 87, 1086-1099.

French, J. L., \& Rosenstein, J. (1984). Employee ownership, work attitudes, and power relationships. Academy of Management Journal, 27, 861-869.

Garland, H. (1990). Throwing good money after bad: The effect of sunk costs on the decision to escalate commitment to an ongoing project. Journal of Applied Psychology, 75, 728-731.

Glaser, B. G. (1963). The local-cosmopolitan scientist. American Journal of Sociology, 69, 249-259.

Gouldner, A. W. (1957). Cosmopolitans and locals: Toward an analysis of latent social roles. Administrative Science Quarterly, 2, 281-306.

Gouldner, A. W. (1958). Cosmopolitans and locals: Toward an analysis of latent social roles. Part II. Administrative Science Quarterly, 2, 444480.

Greene, C. N. (1978). Identification modes of professionals: Relationship with formalization, role strain, and alienation. Academy of Management Journal, 21, 486-492.

Hall, D. T., \& Schneider, B. (1972). Correlates of organizational identification as a function of career pattern and organizational type. Administrative Science Quarterly, 17, 340-350.

Hickson, D. J., \& Thomas, M. W. (1969). Professionalisation in Britain: A preliminary measurement. Sociology, 3, 37-53.

Hogg, M. A., \& Terry, D. J. (2001). Social identity theory and organizational processes. In M. A. Hogg \& D. J. Terry (Eds.), Social identity processes in organizational contexts (pp. 1-12). Philadelphia: Psychology Press.

Ilgen, D. R., Lloyd, J. W., Morgeson, F. P., Johnson, M. D., Meyer, C. J.,
Marrinan, M., et al. (2003). Personal characteristics, knowledge of the veterinary profession, and influences on career choice among students in the veterinary school applicant pool. Journal of the American Veterinary Medical Association, 223, 1587-1594.

Klein, K. J. (1987). Employee stock ownership and employee attitudes: A test of three models. Journal of Applied Psychology, 72, 319-332.

Kuhn, M. H. (1960). Self-attitudes by age, and professional training. Sociological Quarterly, 1, 39-55.

Locke, T. (2001). Curriculum, assessment and the erosion of professionalism. New Zealand Journal of Educational Studies, 36, 5-23.

Long, R. J. (1978). The effects of employee ownership on organizational identification, employee job attitudes, and organizational performance: A tentative framework and empirical findings. Human Relations, 31, $29-48$.

Mael, F. A., \& Ashforth, B. E. (1992). Alumni and their alma mater: A partial test of the reformulated model of organizational identification. Journal of Organizational Behavior, 13, 103-123.

Mael, F. A., \& Tetrick, L. E. (1992). Identifying organizational identification. Educational \& Psychological Measurement, 52, 813-824.

Pedhazur, E. J. (1982). Multiple regression in behavioral research (2nd ed.). New York: Holt, Rinehart \& Winston.

Pierce, J. L., Kostova, T., \& Dirks, K. T. (2001). Toward a theory of psychological ownership in organizations. Academy of Management Review, 26, 298-310.

Pratt, M. G. (1998). To be or not to be? Central questions in organizational identification. In D. A. Whetten \& P. C. Godfrey (Eds.), Identity in organizations: Building theory through conversations (pp. 171-207). Thousand Oaks, CA: Sage.

Pratt, M. G., \& Rafaeli, A. (1997). Organizational dress as a symbol of multilayered social identities. Academy of Management Journal, 40, 862-898.

Saks, A. M., \& Ashforth, B. E. (1997). A longitudinal investigation of the relationships between job information sources, applicant perceptions of fit, and work outcomes. Personnel Psychology, 50, 395-426.

Shamir, B., Zakay, E., Brainin, E., \& Popper, M. (2000). Leadership and social identification in military units: Direct and indirect relationships. Journal of Applied Social Psychology, 30, 612-640.

Smidts, A., Pruyn, A. T. H., \& van Riel, C. B. M. (2001). The impact of employee communication and perceived external prestige on organizational identification. Academy of Management Journal, 44, 1051-1062.

Stahl, M. J., Manley, T. R., \& McNichols, C. W. (1978). Operationalizing the Moskos institution-occupation model: An application of Gouldner's cosmopolitan-local research. Journal of Applied Psychology, 63, 422427.

Tajfel, H., \& Turner, J. C. (1979). An integrative theory of intergroup conflict. In W. G. A. S. Worchel (Ed.), The social psychology of intergroup relations (pp. 33-47). Monterey, CA: Brooks/Cole.

Turner, J. C. (1985). Social categorization and the self-concept: A social cognitive theory of group behavior. In E. J. Lawler (Ed.), Advances in group processes (Vol. 2, pp. 77-122). Greenwich, CT: JAI Press.

van Knippenberg, D., \& van Schie, E. C. M. (2000). Foci and correlates of organizational identification. Journal of Occupational and Organizational Psychology, 73, 137-147.

Wallace, J. E. (1995). Organizational and professional commitment in professional and nonprofessional organizations. Administrative Science Quarterly, 40, 228-255.

Weiss, D. J., Dawis, R. V., \& England, G. W. (1967). Manual for the Minnesota Satisfaction Questionnaire. Minnesota Studies in Vocational Rehabilitation, 22, 120

Received April 22, 2004

Revision received November 9, 2004 Accepted January 24, 2005 